\title{
CONSIDERACIONES SOBRE LA REFORMA DEL SERVICIO PORTUARIO DE MANIPULACIÓN DE MERCANCÍA
}

\author{
ROMÁN EGUINOA DE SAN ROMÁN \\ Universidad Internacional de Cataluña \\ Doctor en Derecho. Profesor asociado de Derecho Administrativo. Abogado
}

\author{
Cómo citar/Citation \\ Eguinoa de San Román, R. (2020). \\ Consideraciones sobre la reforma del servicio portuario de \\ manipulación de mercancía. \\ Revista de Administración Pública, 21 1, 319-348. \\ doi: https://doi.org/10.18042/cepc/rap.211.13
}

\section{Resumen}

La Sentencia del Tribunal de Justicia de la Unión Europea de 11 de diciembre de 2014 (asunto C-576/13) obligó a la reforma del régimen del servicio portuario de manipulación de mercancías en el derecho español, por entender que incumplía las obligaciones que el art. 49 TFUE impone al Estado. La reforma se ha realizado básicamente mediante los Reales Decretos Leyes 8/2017, de 12 de mayo, y 9/2019, de 29 de marzo. El nuevo modelo parece cumplir las exigencias de la sentencia del Tribunal de Justicia de la Unión Europea, pero contiene elementos cuya compatibilidad con otras prescripciones del derecho comunitario es cuestionable. El artículo analiza la reforma, con especial referencia a las condiciones de transición al nuevo modelo desde la perspectiva de las normas comunitarias.

\section{Palabras clave}

Manipulación de mercancías; estiba; libertad de establecimiento; ayudas de Estado; libertad de circulación de trabajadores. 


\section{Abstract}

The sentence of the Court of Justice of the European Union, on 11th December 2014 (C-576/13), forced the reform of the cargo-handling regime on the Spanish Law, by understanding that it didn't accomplish the obligations imposed to the State on the article 49 of the TFEU. The reform has basically been made through the royal decree-law 8/2017 of 12 May, and 9/2019 of 29 March. The new model seems to follow the requirements of the sentence of the Court of Justice of the European Union, but the compatibility of some of its elements respect some prescriptions of Community law is questionable. This article analyzes the reform, with especial reference to the conditions for the transition to the new model from the Community rules perspective.

\section{Keywords}

Cargo-handling; Stowage; Freedom of establishment; State aids; Freedom of movement for workers. 


\section{SUMARIO}

I. INTRODUCCIÓN. II. LA SITUACIÓN ANTERIOR A LA STJUE DE 11 DE DICIEMBRE DE 2014: 1. El servicio portuario de manipulación de mercancías. 2. Las sociedades anónimas de gestión de estibadores portuarios. 3. La contratación de trabajadores. III. LA SENTENCIA DEL TRIBUNAL DE JUSTICIA DE LA UNIÓN EUROPEA DE 11 DE DICIEMBRE DE 2014. IV. EL NUEVO RÉGIMEN DEL SECTOR DE LA ESTIBA: LOS REALES DECRETOS LEYES 8/2017, DE 12 DE MAYO, Y 9/2019, DE 29 DE MARZO: 1. Modificación del ámbito del servicio portuario de manipulación de mercancías. 2. Libertad de contratación de trabajadores. 3. Capacitación de los trabajadores. 4. Los centros portuarios de empleo. 5. Régimen transitorio para la plena aplicación de la nueva regulación: 5. 1. Extinción o transformación en ETT. 5.2. Separación de accionistas. 5.3. Asunción por la Administración portuaria de las indemnizaciones en caso de extinción de contratos de trabajadores portuarios. 5.4. Garantía de utilización del personal de las SAGEP durante el periodo transitorio. 5.5. Subrogación en la posición de las SAGEP. 6. Instrumentos de negociación colectiva. 7. El Real Decreto 257/2019, de 12 de abril, que establece normas para la concesión de ayudas para el sector de la estiba portuaria. V. INCERTIDUMBRES JURÍDICAS DE LA REGULACIÓN APROBADA. VI. RECAPITULACIÓN.

\section{INTRODUCCIÓN}

En el momento de escribir estas páginas se han cumplido cinco años desde que la Sala Sexta del Tribunal de Justicia de la Unión Europea dictó su sentencia sobre la regulación del servicio portuario de manipulación de mercancías en el derecho español (tradicionalmente conocido como servicio de estiba, por lo que utilizaremos también esta expresión para referirnos al mismo, aunque engloba más actividades que la estiba estricta), más concretamente sobre el régimen de gestión de los trabajadores destinados a la prestación del servicio portuario de manipulación de mercancías (Sentencia de 11 de diciembre de 2014, asunto C-576/13).

El Tribunal declaró que obligar a las empresas a participar en las SAGEP para prestar el servicio portuario de manipulación de mercancías y no permitirles recurrir al mercado para contratar su propio personal, sino obligarles a acudir a 
las SAGEP de forma prioritaria, era contrario a la libertad de establecimiento consagrada en el art. 49 TFUE.

El fallo del TJUE echaba por tierra el modelo adoptado por el Estado espańol para los trabajadores de la estiba, modelo que, con algunas variaciones, desde finales de los ańos ochenta había contribuido poderosamente al mantenimiento de la paz social en los puertos de interés general.

La sentencia fue acogida con gran preocupación en el sector. De la dificultad de abordar la situación dan fe tanto el tiempo transcurrido hasta que se acometió la reforma del régimen de la estiba ${ }^{1}$, como el hecho de que el primer intento de regular la reforma por Real Decreto Ley no obtuviera la convalidación del Congreso $^{2}$, como la circunstancia de que hace solo unos meses se dictaron las, hasta esta fecha, últimas normas que la sustancian.

Puede decirse que en la mente del legislador ha pesado tanto la necesidad de dar cumplimiento a la sentencia como la preocupación por la situación de los trabajadores que, en ese momento, desarrollaban su trabajo en el sector de la estiba ${ }^{3}$.

Así, si bien en el nuevo régimen de contratación de trabajadores destinados al servicio portuario de manipulación de mercancías se han suprimido los aspectos cuestionados en su día por la Comisión Europea (ya no habrá obligación de participar en las SAGEP, ni de acudir a ellas para contratar estibadores), simultáneamente se han establecido una serie de condiciones para facilitar la transición al nuevo escenario.

La importancia de algunas de esas condiciones es tal que puede decirse que la viabilidad misma de la aceptación por el sector de la reforma aprobada depende de ellas. He aquí el motivo que nos lleva a escribir estas páginas: dos de las condiciones que estimamos fundamentales para una transición pacífica al nuevo modelo están, en estos momentos, de una u otra forma, pendientes de pronuncia-

1 Más de dos años, lo que comportó la correspondiente resolución condenatoria: STJUE de 13 de julio de 2017, asunto C-388/16, Comisión Europea/Reino de España, en la que el Tribunal resuelve: 1) Declarar que el Reino de España incumplió las obligaciones que le incumbían en virtud del art. 260 TFUE, apdo. 1, al no haber adoptado, en la fecha en que expiró el plazo señalado en el escrito de requerimiento emitido por la Comisión Europea, es decir, el 20 de septiembre de 2015, las medidas que implicaba la ejecución de 11 de diciembre de 2014, Comisión/España (C- 576/13, no publicada, EU:C:2014:2430); 2) Condenar al Reino de España a pagar a la Comisión Europea una cantidad a tanto alzado de 3 millones de euros; 3) Condenar en costas al Reino de Espańa.

2 El Real Decreto Ley 4/2017, de 24 de febrero, fue derogado por Acuerdo del Congreso de los Diputados del 16 de marzo siguiente (BOE, 24 de marzo de 2017).

3 El número total de estibadores se cifraba en 6156 según la Memoria de Análisis de Impacto Normativo del Proyecto de Real Decreto por el que se establecen las normas para la concesión de ayudas especiales para la adaptación del sector de la estiba portuaria, de 1 de abril de 2019, Ministerio de Trabajo, Migraciones y Seguridad Social, Secretaría General Técnica. 
miento de la Comisión Europea. Nuestro objetivo es explicar cuáles son esas condiciones y hacer una aproximación a las mismas a la luz del derecho comunitario.

\section{LA SITUACIÓN ANTERIOR A LA STJUE DE 11 DE DICIEMBRE DE 2014}

La estiba en los puertos de interés general está regulada en el texto refundido de la Ley de Puertos del Estado y de la Marina Mercante (Real Decreto Legislativo 2/2011, de 5 de septiembre, en lo sucesivo TRLPEMM).

La regulación original del servicio portuario en dicho texto se mantiene en lo sustancial hoy en día, si bien como consecuencia de la STJUE de 11 de diciembre de 2014 se ha modificado la regulación del régimen de gestión de la puesta a disposición de trabajadores portuarios, que se contenía en el capítulo VI del título VI del libro primero del TRLPEMM.

\section{EL SERVICIO PORTUARIO DE MANIPULACIÓN DE MERCANCÍAS}

De acuerdo con el art. 130.1 del TRLPEMM, integran el servicio portuario de manipulación de mercancías las actividades de carga, estiba, desestiba, descarga y trasbordo de mercancías, objeto de tráfico marítimo, que permitan su transferencia entre buques, o entre estos y tierra u otros medios de transporte. Para tener la consideración de actividades incluidas en este servicio deberán realizarse íntegramente dentro de la zona de servicio del puerto y guardar conexión directa e inmediata con una concreta operación de carga, descarga o trasbordo de un buque determinado ${ }^{4}$.

Rige en los servicios portuarios el principio de libre acceso a la prestación previa obtención de licencia otorgada por la Autoridad Portuaria, en un sistema en el que el otorgamiento de licencias para la prestación de servicios portuarios es reglado (arts. 109.2 y 115.1 TRLPEMM), salvo supuestos específicos, como el de limitación del número de prestadores (art. 111.4 TRLPEMM) ${ }^{5}$.

4 Esta definición del ámbito del servicio se completa en los apdos. 2 (que define los supuestos que no tienen consideración de mercancías objeto de tráfico marítimo) y 3 (que relaciona una serie de actividades exentas de la consideración de servicio portuario de manipulación de mercancías; como veremos este apartado se ha modificado por el Real Decreto Ley 9/2019).

5 Aunque con matices, puede decirse que la regulación de los servicios portuarios que se hace en el TRLPEMM está en línea con la que establece el reciente Reglamento (UE) 2017/352, del Parlamento Europeo y del Consejo, de 15 de febrero, por el que se crea un marco para la prestación de servicios portuarios y se adoptan normas comunes sobre la transparencia financiera de los puertos y, en ese sentido, es respetuosa con las libertades fundamentales del derecho comunitario. Sobre el Reglamento (UE) 2017/352 puede ver- 
No obstante su indudable relevancia para la explotación portuaria, la titularidad de los servicios portuarios no se reserva al sector público. Legalmente se trata de actividades privadas, cuya libre prestación corresponderá normalmente a los operadores económicos privados, de suerte que solo en defecto de la iniciativa privada podrá la Administración pública portuaria participar en la prestación de servicios portuarios (arts. 109.3 y 111.5 TRLPEMM). De ahí que no puedan considerarse servicios públicos en el sentido estricto clásico de dicha categoría jurídica, sin perjuicio de que pueda afirmarse su carácter de servicios esenciales, que justifica su sometimiento a licencia —en lugar de concesión-y, en definitiva, su regulación legal y las potestades de intervención de la Administración portuaria ${ }^{6}$.

\section{LAS SOCIEDADES ANÓNIMAS DE GESTIÓN DE ESTIBADORES PORTUARIOS}

En el caso del servicio portuario de manipulación de mercancías, la obtención de la licencia para prestar dicho servicio obligaba al titular de la misma (excepto en el supuesto de autoprestación) a participar en una sociedad anónima de gestión de estibadores portuarios (SAGEP) y a acudir a ella prioritariamente para contratar trabajadores para el servicio. La tenencia de una licencia en vigor para prestar el servicio portuario de manipulación era condición sine qua non para poder ser accionista de la SAGEP y ningún titular de licencia podía separarse de la SAGEP (art. 143.1 y 5 TRLPEMM derogado por el Real Decreto Ley 8/2017).

Las SAGEP eran sociedades que debían estar formadas exclusivamente por los titulares de licencia para la prestación del servicio en el puerto de que se tratara $^{7}$, con excepción de los supuestos de autoprestación, y su objeto consistía en la gestión de la puesta de sus trabajadores a disposición de sus accionistas o de

se, entre otros, VV. AA. (2019), El Reglamento Europeo de Puertos y su impacto en el sector, Barcelona: Atelier.

6 Sobre el concepto de servicios esenciales a que nos referimos puede verse M. Y. Fernández García (2003), Estatuto Jurídico de los Servicios Esenciales Económicos en Red, Ciudad Argentina: INAP. Específicamente sobre los servicios portuarios, puede verse G. Ariño Ortiz (2004), El Régimen de prestación de servicios en los puertos de interés general en La nueva legislación portuaria (Comentarios a la Ley 48/2003, de 26 de noviembre, de Régimen Económico y de Prestación de Servicios de los Puertos de Interés General, Barcelona: Atelier, págs. 19-44; también, R. Eguinoa de San Román (2012), La gestión de los puertos de interés general, Barcelona: Atelier, págs. 337-349.

7 La ley establecía que el capital social inicial se fijaba en los Estatutos de la SAGEP distribuyéndose entre los titulares de licencias en vigor en el puerto en el momento de la constitución de la SAGEP, según los siguientes criterios: el 50\% del capital se distribuirá proporcionalmente entre el número de titulares de licencias del servicio; el restante 50\% se distribuirá entre dichos titulares en función del grado de utilización temporal de la plantilla, medido en volumen de facturación, estableciendo un mecanismo de reajuste (art. 143.2, 3 y 4, derogado). 
empresas autorizadas para la realización de determinadas actividades (art. 142.1 TRLPEMM, derogado) ${ }^{8}$.

\section{LA CONTRATACIÓN DE TRABAJADORES}

Los titulares de licencia para la prestación del servicio portuario de manipulación de mercancías, cuando necesitaban trabajadores para prestar el servicio y querían contratarlos en régimen laboral común, debían acudir a la SAGEP y hacer una oferta nominativa o innominada a sus trabajadores. Solo en caso de que no hubiera personal adecuado o en número suficiente o la oferta no fuera aceptada podrían dichas empresas acudir libremente a otras fuentes para la contratación; eso sí, siempre deberían ser trabajadores con la cualificación requerida legalmente (art. 150.1 TRLPEMM, derogado).

La otra posibilidad que tenían los titulares de licencia para la prestación del servicio portuario de manipulación de mercancías era la demanda a la SAGEP de asignación de trabajadores que mantenían su relación laboral especial con esta (art. 151 TRLPEMM, derogado). En el caso de que, por cualquier causa, la SAGEP no pudiera responder a la demanda de trabajadores y no concurrieran las circunstancias previstas en sus estatutos para incrementar el número de trabajadores por ella contratados, las empresas estibadoras podrían contratar directamente a trabajadores que reunieran la cualificación exigida por la ley, sin exceder de un turno de trabajo.

Este régimen afectaba también a los titulares de licencia para la prestación del servicio portuario de manipulación de mercancías que estaban exentos de formar parte de las SAGEP. Así, la ley establecía que tales empresas estibadoras, cuando su personal fijo no pudiera atender la carga puntual de trabajo, estaban obligadas a solicitar la puesta a disposición del personal de la SAGEP y solo si esta no podía atender la petición podrían contratar libremente el personal que necesitaran, eso sí, sin que la contratación pudiera exceder un turno de trabajo (art. 151.5 TRLPMM, derogado).

En los casos de asignación de trabajadores en régimen laboral especial, la SAGEP mantenía la condición de empresario, si bien las facultades de dirección y control de la actividad quedaban en manos de la empresa estibadora, que además era la responsable del cumplimiento de la normativa de seguridad y salud laboral, recargo de prestaciones por accidente de trabajo o enfermedad profesional en el centro de trabajo durante el periodo de puesta a disposición que tuviera causa

8 En ese sentido, señala la doctrina: «Las actuales SAGEP son una sociedad de cesión de trabajadores que tienen como finalidad formar a los trabajadores para cederlos previo llamamiento diario o previa cesión con suspensión de la relación especial a la empresa estibadora que, en este segundo caso, contrata a través de una relación de trabajo ordinario» (I. Ballester Pastor 2014, La relación laboral especial de los estibadores portuarios, Valencia: Tirant lo Blanch, pág. 95). 
en la falta de adopción de las medidas de seguridad e higiene (art. 151.7 y 8 TRLPEMM, derogado).

Las empresas autorizadas para la realización de actividades comerciales que no tenían la consideración de servicio portuario de manipulación de mercancías de acuerdo con el art. 130.3.c TRLPEMM estaban legalmente obligadas a atender sus necesidades de personal para esas actividades mediante la utilización de personal de la SAGEP siempre y cuando su oferta fuera igual o más ventajosa en términos de calidad y coste en el sector de la estiba (art. 155 TRLPEMM, derogado).

Los trabajadores que desarrollaran su actividad en el servicio portuario de manipulación de mercancías podían establecer una relación laboral tanto con las SAGEP, en el régimen laboral especial del art. 2.1.h del antiguo texto refundido de la Ley del Estatuto de los Trabajadores ${ }^{9}$, como con las empresas titulares de licencia para prestar dicho servicio, en régimen laboral común (art. 149.1 TRLPEMM, derogado).

La ley potenciaba la contratación de trabajadores en régimen laboral común por las empresas estibadoras. En ese sentido, era obligado incluir como una de las condiciones de las licencias del servicio portuario de manipulación de mercancías un porcentaje mínimo de trabajadores (que en todo caso debería cubrir, al menos, el 25\% de la actividad de la empresa en cómputo interanual en el ámbito de ese servicio) que debían tenerse contratados en régimen laboral común (arts. 117.1.n y 150.4 TRLPEMM, derogados).

Ese objetivo se afianzaba también con un sistema de premios y sanciones a través de los títulos concesionales: los pliegos de bases de los concursos para adjudicar concesiones demaniales cuyo titular fuera a prestar el servicio portuario debían incluir, como criterio de adjudicación, el compromiso del licitador de contratar trabajadores en régimen laboral común por encima del mínimo fijado en el pliego; el incumplimiento de dicho compromiso era causa de caducidad de la concesión, previa sanción; además, la ley sancionaba expresamente con la nulidad a los acuerdos de las Autoridades Portuarias que no respetaran esta regulación (arts. 82.2.d, 98.1.1 y 150.5 TRLPEMM derogados).

Por otra parte, se configuraba como causa de extinción de la relación laboral especial que unía a aquellos con la SAGEP, el rechazo reiterado por el trabajador de ofertas, adecuadas a su categoría profesional, de empresas titulares de licencia del servicio portuario de manipulación que deseasen establecer con el trabajador una relación laboral común (art. 151.3. TRLPEMM, derogado).

Para concluir, conviene recordar que la ley exigía una formación específica para desarrollar las actividades que integraban el servicio portuario, que era determinada por Orden del Ministerio de Fomento (arts. 153 y 154 TRLPEMM, derogados).

9 Respecto de estos trabajadores correspondía a la SAGEP el cumplimiento de las obligaciones salariales y de Seguridad Social (art. 151.6 TRLPEMM, hoy derogado). 


\section{LA SENTENCIA DEL TRIBUNAL DE JUSTICIA DE LA UNIÓN EUROPEA DE 11 DE DICIEMBRE DE 2014}

Sobre el marco regulador de la estiba que se acaba de describir vino a incidir la Sentencia del Tribunal de Justicia de la Unión Europea de 11 de diciembre de 2014.

El Tribunal resuelve un recurso por incumplimiento interpuesto por la Comisión Europea el 14 de noviembre de 2013, por el que pedía que se declarase que el Reino de España había incumplido las obligaciones que le correspondían en virtud del art. 49 TFUE al obligar con carácter general a las empresas estibadoras que operan en sus puertos de interés general a inscribirse en una SAGEP y al no permitirles recurrir al mercado para contratar su personal.

Recuerda el Tribunal (36) su reiterada jurisprudencia según la cual «el art. 49 TFUE se opone a cualquier medida nacional que, aun cuando se aplique sin discriminación alguna por razón de la nacionalidad, pueda obstaculizar o hacer menos atractivo el ejercicio, por parte de los nacionales de la Unión, de la libertad de establecimiento garantizada por el Tratado».

Tal como señalaba la Comisión, el Tribunal entiende (37) que «aun cuando las obligaciones que impone el régimen portuario español se aplican de modo idéntico tanto a los operadores establecidos en Espańa como a aquellos que provienen de otros Estados miembros, tales obligaciones pueden tener como resultado impedir a esta última categoría de operadores establecerse en los puertos espańoles de interés general para desarrollar en ellos una actividad de manipulación de mercancías, [dado que] compelen a las empresas estibadoras extranjeras a llevar a cabo una adaptación que puede tener consecuencias financieras y producir perturbaciones en su funcionamiento, hasta el punto de disuadir a las empresas de otros Estados miembros de establecerse en los puertos españoles de interés general».

Establecido que las obligaciones del régimen portuario español constituyen una restricción a la libertad de establecimiento a efectos del art. 49 TFUE, el tribunal analiza las justificaciones que ofrece el Reino de Espańa (por una parte, la protección de los trabajadores y, por otra, garantizar la regularidad, continuidad y calidad del servicio portuario), y, si bien reconoce que pueden ser objetivos legítimos, concluye que España no ha demostrado ni la necesidad, ni la proporcionalidad de la restricción ${ }^{10}$.

10 «(53) [...], la circunstancia de que el régimen portuario español persiga un objetivo legítimo no es suficiente para justificar válidamente la restricción de que se trata. En efecto, según jurisprudencia reiterada del Tribunal de Justicia, la aplicación de una normativa de un Estado miembro que persiga un objetivo legítimo debe ser indispensable para garantizar la consecución de éste. En otros términos, es necesario que el mismo resultado que se persigue con la normativa en cuestión no pueda conseguirse mediante normas menos rigurosas. [...] (55) Por otra parte, cabe observar que existen medidas que son 
Por esto el tribunal considera fundado el recurso por incumplimiento y declara que el Reino de España ha incumplido las obligaciones que le incumben en virtud del art. 49 TFUE, al imponer a las empresas de otros Estados miembros que deseen desarrollar la actividad de manipulación de mercancías en los puertos españoles de interés general tanto la obligación de inscribirse en una Sociedad Anónima de Gestión de Trabajadores Portuarias y, en su caso, de participar en el capital de esta, por un lado, como la obligación de contratar con carácter prioritario a trabajadores puestos a disposición por dicha Sociedad Anónima, y a un mínimo de tales trabajadores sobre una base permanente, por otro lado.

\section{EL NUEVO RÉGIMEN DEL SECTOR DE LA ESTIBA: LOS REALES DECRETOS LEYES 8/2017, DE 12 DE MAYO, Y 9/2019, DE 29 DE MARZO}

El marco legal actual de la estiba lo establecen el Real Decreto Ley 8/2017, de 12 de mayo ${ }^{11}$, "por el que se modifica el régimen de los trabajadores del servicio portuario de manipulación de mercancías dando cumplimiento a la Sentencia del Tribunal de Justicia de la Unión Europea de 11 de diciembre de 2014, recaída en el asunto C-576/13 (procedimiento de infracción 2009/4052) y el Real Decreto Ley 9/2019, de 29 de marzo ${ }^{12}$, por el que se modifica la Ley 14/1994 de 1 de junio, por el que se regulan las empresas de trabajo temporal para su adaptación a la actividad de la estiba portuaria y se concluye la adaptación legal del régimen de los trabajadores para la prestación del servicio portuario de manipulación de mercancías».

Los principales elementos del nuevo régimen pueden resumirse como sigue.

menos restrictivas que las aplicadas por el Reino de España y que, al mismo tiempo, son idóneas para conseguir un resultado similar y para garantizar tanto la continuidad, regularidad y calidad del servicio de manipulación de mercancías como la protección de los trabajadores. De este modo, por ejemplo, tal como sugiere la Comisión, cabría la posibilidad de prever que sean las propias empresas estibadoras las que, pudiendo contratar libremente trabajadores permanentes o temporales, gestionen las oficinas de empleo que han de suministrarles su mano de obra y organicen la formación de esos trabajadores, o la posibilidad de crear una reserva de trabajadores gestionada por empresas privadas, que funcionen como agencias de empleo temporal y que pongan trabajadores a disposición de las empresas estibadoras".

11 Convalidado el 18 de mayo de 2017 (BOE de 19 de mayo de 2017).

12 Convalidado el 3 de abril de 2019 (BOE de 10 de abril de 2019). 


\section{MODIFICACIÓN DEL ÁMBITO DEL SERVICIO PORTUARIO DE MANIPULACIÓN DE MERCANCÍAS}

Tras la reforma se mantiene la definición del ámbito del servicio de manipulación de mercancías, si bien pasa a tener la consideración de actividad que forma parte del mismo la actividad de embarque y desembarque de vehiculos a motor sin matricular (disposición derogatoria del Real Decreto Ley 8/2017, que suprime el antiguo inciso final del art. 130.3.c TRLPMM).

\section{LIBERTAD DE CONTRATACIÓN DE TRABAJADORES}

Se establece la libertad de contratación de trabajadores portuarios para la prestación del servicio portuario de manipulación de mercancías y se desvincula expresamente la prestación del servicio de la necesidad de participar en SAGEP o similares (art. 2 del Real Decreto Ley 8/2017).

Además, se derogan los preceptos del TRLPEMM que imponían la obligatoriedad de formar parte de una SAGEP para prestar el servicio portuario de manipulación de mercancías y la obligatoriedad de contratar de forma prioritaria a trabajadores de una SAGEP (disposición derogatoria del Real Decreto Ley 8/2017).

\section{CAPACITACIÓN DE LOS TRABAJADORES}

Para poder trabajar en la prestación del servicio portuario de manipulación de mercancías lo único que se exige es cumplir los requisitos de capacitación que establece el art. 3 del Real Decreto Ley 8/2017: haber obtenido el certificado de profesionalidad del anexo VIII del Real Decreto 988/2013, de 13 de diciembre, por el que se establecen nueve certificados de profesionalidad de la familia profesional marítimo-pesquera.

También podrán realizar actividades incluidas en este servicio portuario los trabajadores de los grupos 0 y 1 del IV Acuerdo para la regulación de las relaciones laborales en el sector de la estiba portuaria o que en el futuro los sustituyan, que, bajo contrato para la formación y el aprendizaje, se encuentren cursando el citado certificado de profesionalidad ${ }^{13}$.

El certificado de profesionalidad no será exigible en dos supuestos concretos: a) trabajadores que acrediten haber realizado con anterioridad a la entrada en vigor del Real Decreto Ley 8/2017 más de 100 jornadas de trabajo en este servicio portuario en cualquier Estado miembro así como en tareas de carga, estiba, desestiba, descarga y trasbordo de mercancías que hubieran estado excluidas del servicio ex art. 2,g del Real Decreto Ley 2/1986, de 23 de mayo (la acreditación

13 Este supuesto de capacitación fue añadido por el Real Decreto Ley 9/2019. 
debe homologarse por Puertos del Estado), y b) el personal de buque que realice a bordo dichas actividades en las condiciones permitidas por el TRLPEMM.

\section{LOS CENTROS PORTUARIOS DE EMPLEO}

Las empresas que presten el servicio portuario de manipulación de mercancías podrán contratar los trabajadores que precisen para prestar dicho servicio bien directamente o bien a través de empresas que se dediquen a la puesta a disposición de esos trabajadores.

El art. 4 del Real Decreto Ley 8/2017 prevé la existencia de centros portuarios de empleo (en lo sucesivo CPE) ${ }^{14}$, cuyo objeto sea el empleo de los trabajadores portuarios en el servicio portuario de manipulación de mercancías, así como su cesión temporal a empresas titulares de licencia de prestación de dicho servicio portuario o de autorización de servicios comerciales portuarios. Pueden coexistir varios en un mismo puerto.

Esta figura ha sido regulada por el Real Decreto Ley 9/2019 mediante la incorporación del nuevo capítulo V (arts. 18 a 21) ${ }^{15}$ a la Ley 14/1994, de 1 de junio, por la que se regulan las empresas de trabajo temporal.

Según el nuevo art. 18.1 de la Ley 14/1994, los CPE tienen por exclusivo objeto el empleo de trabajadores de la estiba portuaria para su puesta a disposición, de forma temporal, de las empresas titulares de licencia de prestación de servicio portuario de manipulación de mercancías o de autorización de servicios comerciales portuarios, así como la formación profesional de aquellos. La constitución de los CPE queda reservada a empresas que tengan la licencia para la prestación del servicio portuario (nuevo art. 18.2 Ley 14/1994) ${ }^{16}$.

En cuanto a los requisitos para pedir la autorización administrativa para operar como CPE, el art. 18 introduce una serie de singularidades respecto de lo

14 La doctrina laboralista ha criticado el Real Decreto Ley 8/2017 señalando, entre otras cuestiones, que contribuye a la precarización del trabajo de los estibadores y que ha hecho desaparecer los incentivos a la contratación indefinida. Así, J. Cabeza Pereiro (2017), «Algunos interrogantes acerca de los centros portuarios de empleo» y F. Fernández Prol (2017), «Relación laboral de estiba portuaria y libertad de establecimiento: la respuesta en derecho interno", ambos en VV. AA., Retos presentes y futuros de la política maritima integrada de la Unión Europea, Editorial Boch, págs. 201-222 y 225-248, respectivamente. La EM justifica el tratamiento singular de los CPE en dos argumentos: a) el hecho de que limiten su campo de actuación a la estiba portuaria, lo que supone que solo pondrán trabajadores a disposición de empresas con licencia para prestar el servicio portuario de manipulación de mercancías o con autorización para prestar servicios comerciales, y b) el hecho de que la gran mayoría del personal perteneciente a los CPE cuenta con un contrato de trabajo por tiempo indefinido.

16 El Real Decreto Ley 8/2017 no establecía este requisito (véase el art. 4), si bien su disposición transitoria segunda sí hacía referencia a esa posibilidad al regular cómo se podía alcanzar el porcentaje de contratación de personal proveniente de la SAGEP. 
que se pide para operar como «simple» empresa de trabajo temporal: aparte de exigir que en la denominación aparezca "centro portuario de empleo» o CPE, la estructura organizativa y las garantías se fijan, respectivamente, por referencia al número de días de puesta a disposición y el porcentaje de masa salarial del personal de estiba contratado temporalmente el año anterior (apdos. 2.b y 3 del art. 18$)^{17}$.

Según el art. 19, los contratos de puesta a disposición de trabajadores de los CPE podrán celebrarse para cubrir necesidades de personal de estiba propias del servicio de manipulación de mercancías de las empresas titulares de licencias para la prestación del mismo o de autorización de servicios comerciales. Los contratos de los CPE con los trabajadores podrán ser indefinidos o de duración determinada (art. 20 Ley 14/1994).

Como sucedía en la regulación anterior, se reserva a las empresas titulares de las licencias del servicio portuario de manipulación de mercancías las potestades de dirección, organización y control de la actividad laboral de los trabajadores portuarios puestos a su disposición por los CPE (art. 21 de la Ley 14/1994).

\section{RÉGIMEN TRANSITORIO PARA LA PLENA APLICACIÓN DE LA NUEVA REGULACIÓN}

Los reales decretos leyes que comentamos establecen un régimen transitorio para facilitar el paso a la plena aplicación de la nueva regulación, atendido el impacto de la misma en el sector. Dicho régimen consiste básicamente en lo siguiente.

\subsection{Extinción o transformación en ETT}

El apdo. 1 de la disposición transitoria primera del Real Decreto Ley 8/2017 establece un plazo de tres años desde la entrada en vigor del Real Decreto Ley, durante el cual las SAGEP pueden subsistir ${ }^{18}$ manteniendo su objeto de puesta a disposición de trabajadores portuarios a los titulares de licencias del servicio portuario o de autorizaciones para servicios comerciales, sin exigir para esto que sean o no accionistas de la sociedad.

17 El precepto no concreta la procedencia geográfica de esta referencia. Parece necesario concretaría puesto que los CPE no se configuran como sucesores legales de las SAGEP y además el ámbito geográfico de los CPE puede alcanzar a todo el territorio nacional y coexistir varios en un mismo puerto, a diferencia de las SAGEP, que estaban vinculadas a un ámbito portuario determinado.

18 Tal subsistencia no es obligatoria, puesto que la propia disposición transitoria primera admite que puedan extinguirse antes de ese plazo («subsistirán, salvo que se extingan con anterioridad»). La extinción se regirá por lo dispuesto en el apdo. 3 de esta misma disposición. 
Expirado ese periodo, las SAGEP que aún subsistan pueden extinguirse o, previa obtención de la pertinente autorización ex art. 2 Ley 14/1994, seguir como ETT en concurrencia con las demás ETT y con los CPE que se hayan constituido.

Hasta su regulación como ETT o su extinción, «los accionistas de la SAGEP responderán de la totalidad de los pasivos y obligaciones de la sociedad, personal y mancomunadamente entre sí, en proporción a su participación en el capital social».

\subsection{Separación de accionistas}

Según el apdo. 3 de la disposición transitoria primera, en el plazo de seis meses de ese periodo transitorio (es decir, desde la entrada en vigor del Real Decreto Ley), los miembros de las SAGEP deben decidir individualmente si desean continuar o no formando parte de las mismas; en este último caso podrán hacerlo antes de la finalización de ese periodo, procediendo a vender sus acciones a los que deseen continuar, a prorrata de la participación de cada uno de ellos y los accionistas que deseen continuar deberán adquirirlas por su valor neto contable. Si la venta no puede efectuarse en todo o en parte en el plazo máximo de seis meses desde la comunicación de separación, las correspondientes acciones serán amortizadas con cargo a la SAGEP, con la consiguiente reducción de capital.

Tras la separación, los accionistas que permanezcan podrán acordar una nueva redistribución del capital y admitir nuevos accionistas voluntarios. Si ningún accionista desea seguir, la SAGEP se disolverá de acuerdo con las reglas de la ley de sociedades de capital.

\subsection{Asunción por la Administración portuaria de las indemnizaciones en caso de extinción de contratos de trabajadores portuarios}

Según el apdo. 4 de la disposición transitoria primera, para «igualar la posición competitiva entre los actuales titulares de licencias de prestación del servicio portuario de manipulación de mercancías con aquellos nuevos que accedan a la prestación", en caso de extinción de contratos laborales de trabajadores de las SAGEP anteriores al 11 de diciembre de 2014 o de contratos de empresas titulares de licencias de prestación del servicio portuario de manipulación de mercancías con trabajadores procedentes de las SAGEP celebrados por imperativo legal con anterioridad a dicha fecha, por cualquiera de las causas de los arts. 51 y 52 del texto refundido del Estatuto de los Trabajadores (despido colectivo y despido por causas objetivas), las Autoridades Portuarias asumirán obligatoriamente el 100\% de la indemnización correspondiente en la cuantía del art. 53 de dicho texto legal generada desde la celebración de los contratos hasta su extinción o hasta la finalización del periodo transitorio si fuera anterior.

Para ello la Autoridad Portuaria del ámbito geográfico de la SAGEP donde los trabajadores estuvieron contratados, previa verificación de la documentación 
presentada, abonará la indemnización correspondiente a cada trabajador al empleador de los mismos en el momento de la extinción contractual, distribuida en un periodo de tres años a partir de la solicitud ${ }^{19}$.

Esta medida podría revestir los caracteres de una ayuda de Estado. De ahí que el apdo. 2 de la disposición final quinta establezca que no entrará en vigor hasta la expresa declaración por la Comisión Europea de su compatibilidad con el régimen de ayudas de Estado.

\subsection{Garantía de utilización del personal de las SAGEP durante el periodo transitorio}

Para garantizar que las SAGEP mantengan un cierto grado de actividad durante el período transitorio para financiarse, la disposición transitoria segunda establece que durante dicho periodo los titulares de licencias de prestación del servicio portuario de manipulación de mercancías — salvo aquellos que operen en régimen de autoprestación — están obligados a cubrir una parte de su actividad con trabajadores portuarios procedentes de la SAGEP, bien puestos a disposición por las SAGEP o, provenientes de las SAGEP, puestos a disposición por un CPE o una ETT de los que no sea partícipe la empresa obligada, o bien incorporando dichos trabajadores a su plantilla o a la de CPE o ETT de los que forme parte la empresa obligada ${ }^{20}$.

19 Ha de entenderse que quien ha de solicitar el desembolso de la indemnización es el empleador y debe aportar la documentación justificativa y acreditativa correspondiente. Una vez determinada su adecuación al Real Decreto Ley se abonará por la Autoridad Portuaria.

El Real Decreto Ley establece que si el empleador es sujeto pasivo de tasas portuarias, la Autoridad Portuaria acordará que las indemnizaciones asumidas minoren los importes de las cuotas de dichas tasas. Parece lógico entender que esa minoración sustituirá la obligación de la Autoridad Portuaria de desembolsar las indemnizaciones o la disminuirá en la parte que se haya minorado la cuota tributaria.

Concretamente, se dice que «deberán cubrir en cómputo interanual con trabajadores de la SAGEP del puerto correspondiente existentes a la entrada en vigor de este real Decreto Ley durante el primer año como mínimo el 75\% de las actividades de la empresa integradas en el servicio portuario de manipulación de mercancías y las actividades comerciales que no tengan la consideración de servicio portuario de manipulación de mercancías de acuerdo con lo previsto en el inciso final del artículo 130.3.c del texto refundido de la Ley de Puertos del Estado y de la Marina Mercante, en este último caso siempre y cuando su oferta sea igual o más ventajosa en términos de calidad y coste en el sector de la estiba. Dicho porcentaje será del 50\% durante el segundo año del referido periodo transitorio y del $25 \%$ durante el tercer año. La asignación de trabajadores y su coste se hará en igualdad de condiciones para todas las empresas, sean o no accionistas de la SAGEP». 


\subsection{Subrogación en la posición de las SAGEP}

El Real Decreto Ley 9/2019 viene a completar el régimen transitorio que estamos exponiendo al establecer que las organizaciones sindicales y empresariales pueden acordar medidas para «el mantenimiento de los derechos de los trabajadores con el fin de garantizar el principio de calidad y estabilidad en el empleo, así como la protección de los derechos de los trabajadores».

Concretamente, establece que "con el fin de garantizar el principio de estabilidad en el empleo, las organizaciones sindicales y asociaciones empresariales podrán establecer, mediante un acuerdo o un convenio colectivo ${ }^{21}$, las medidas de subrogación necesarias para el mantenimiento del empleo de los trabajadores que», a la entrada en vigor del Real Decreto Ley 8/2017, «estuvieran prestando servicios portuarios de manipulación de mercancías y sigan prestándolo a la entrada en vigor del presente, en los supuestos previstos en los siguientes apartados» (art. 4.1 del Real Decreto Ley 9/2019).

Los supuestos citados son dos:

a) Subrogación de empresas titulares de la licencia para prestar el servicio portuario de manipulación de mercancías en la posición de la SAGEP (art. 4.2). Se trata de una subrogación por acuerdo o convenio colectivo cuando las empresas titulares de licencia para la prestación del servicio portuario opten por dejar la SAGEP con decrecimiento de la actividad o cuando las empresas acuerden la disolución de la SAGEP (ambos casos están contemplados en la disposición transitoria primera del Real Decreto Ley 8/2017); el mecanismo de subrogación deberá ser transparente, objetivo y equitativo, de acuerdo con los principios y garantías que informan el art. 44 ET y

b) Subrogación de CPE en la posición de la SAGEP (art. 4.3). En este último supuesto, el CPE se subrogará en la posición de empleador de los trabajadores de la SAGEP una vez consumada la sucesión de la actividad de puesta a disposición de los mismos, respetando en todo caso lo establecido en el art. 44 ET.

\section{INSTRUMENTOS DE NEGOCIACIÓN COLECTIVA}

El Real Decreto Ley 8/2017 y el Real Decreto Ley 9/2019 daban un plazo para la adaptación de las normas convencionales con advertencia de que, pasado

21 Las facultades conferidas a los agentes sociales por este artículo podrán ejercerse exclusivamente durante el periodo transitorio establecido en el Real Decreto Ley 8/2017 (art. 4.4 Real Decreto Ley 9/2019). 
el plazo, las normas no adaptadas serían nulas de pleno derecho ${ }^{22}$, pero sin duda lo más relevante en cuanto a los instrumentos de negociación colectiva se contiene en la disposición adicional segunda del Real Decreto Ley 8/2017.

Dicha disposición adicional segunda extiende el régimen de prioridad aplicativa del art. 84.2 del Estatuto de los Trabajadores a los convenios de empresa y de grupos de empresa o de pluralidad de empresas vinculadas por razones organizativas y productivas y nominativamente identificadas, a los "convenios colectivos que se negocien de conformidad con lo dispuesto en el art. 87.1 del Estatuto de los Trabajadores por una pluralidad de empresas que estén vinculadas en razón de su adscripción a un mismo puerto y nominativamente identificadas».

\section{EL REAL DECRETO 257/2019, DE 12 DE ABRIL, QUE ESTABLECE NORMAS PARA LA CONCESIÓN DE AYUDAS PARA EL SECTOR DE LA ESTIBA PORTUARIA}

Finalmente, mediante Real Decreto 257/2019, de 12 de abril, con el objetivo de colaborar con los principios de estabilidad en el empleo y de mejora de productividad de las empresas, se ha establecido un procedimiento de concesión directa de ayudas a los estibadores portuarios de mayor edad condicionadas a que voluntariamente rescindan su contrato de trabajo.

El régimen tiene por finalidad facilitar «las salidas voluntarias de los trabajadores de mayor edad en las mejores condiciones y contribuir así a la necesaria reestructuración del sector de la estiba» (art. 2). Entre las circunstancias para ser beneficiario de la ayuda se exige, aparte de la rescisión voluntaria del contrato laboral, tener una edad inferior en 60 meses, como máximo, a la edad ordinaria de jubilación, tener cubierto el periodo de cotización exigido para causar derecho a la pensión de jubilación en su modalidad contributiva y estar prestando servicio como estibador portuario en SAGEP antes del 11 de diciembre de 2014 y continuar en la misma, o, en su caso, en una empresa titular de licencia del servicio portuario de manipulación de mercancías o en un CPE en los que se hayan incorporado mediante subrogación con posterioridad al 14 de mayo de 2017, hasta el inicio de la ayuda (art. 4).

22 El plazo era de un año en el Real Decreto Ley 8/2017 (disposición adicional primera, apdo. 1) y de nueve meses en el Real Decreto Ley 9/2019 (disposición adicional segunda). El primero de ellos, además, permitía la rescisión del contrato de trabajo cuando la modificación del convenio colectivo les causara un perjuicio sustancial con una indemnización en la cuantía prevista en el art. 41 del Estatuto de los Trabajadores; esto debería producirse en el plazo de tres meses desde la entrada en vigor de las normas convencionales de adaptación a dicho Real Decreto Ley y siempre que se produzca en el plazo del año desde la entrada en vigor de este (disposición adicional primera, apdo. 2). 


\section{INCERTIDUMBRES JURÍDICAS DE LA REGULACIÓN APROBADA}

1. El nuevo régimen de los trabajadores del servicio portuario de manipulación de mercancías ha suprimido los concretos aspectos de la regulación anterior que el Tribunal de Justicia de la UE señaló como determinantes del incumplimiento por el Reino de Espańa de las obligaciones derivadas del art. 49 TFUE. Tras la reforma, las empresas que quieran prestar el servicio en nuestro país no tienen que formar parte de ninguna sociedad en concreto ni deben acudir a ninguna sociedad en concreto para contratar sus trabajadores.

Ahora bien, la conformidad al derecho comunitario de las medidas que han de permitir la transición al nuevo régimen no es tan evidente. $\mathrm{Al}$ margen de que la garantía de tres años de utilización del personal de las SAGEP (disposición transitoria $2^{\text {a }}$ del Real Decreto Ley 8/2017) prolonga de alguna forma, siquiera sea provisionalmente, el régimen que ha sido declarado contrario al art. 49 TFUE, hay dos medidas fundamentales para la transición sobre las que recae la sombra de la duda.

Se trata de la asunción por parte del Estado del coste de las indemnizaciones por eventuales despidos de trabajadores portuarios con contrato antes del $11 \mathrm{de}$ diciembre de 2014 y la subrogación de las empresas estibadoras en la posición de la SAGEP a la que pertenecen, en caso de que quieran abandonarla o de disolución de esta.

2. La asunción por las Autoridades Portuarias del coste de los despidos de los trabajadores portuarios (apdo. 4 de la disposición transitoria primera del Real Decreto Ley 8/2017).

La DT 1a.4 del Real Decreto Ley 8/2017 establece que los organismos públicos gestores de los puertos de interés general, en caso de que los contratos laborales de trabajadores portuarios vigentes antes del 11 de diciembre de 2014, «en cualquier momento posterior a la entrada en vigor del presente real decreto ley», se extingan por cualquiera de las causas contempladas en los arts. 51 y 52 ET, deberán abonar a sus empleadores (fueran SAGEP en caso de contratos de régimen especial o fueran empresas titulares de licencias para la prestación del servicio portuario de mercancías en caso de contratos de régimen laboral común) el $100 \%$ de las indemnizaciones procedentes por esta causa en la cuantía prevista en el art. 53 de dicho texto legal, generadas desde la celebración de los contratos hasta su extinción o hasta la finalización del periodo transitorio si fuera anterior.

Es decir que, en caso de extinción de contratos de trabajadores portuarios preexistentes a la sentencia del TJUE por despido colectivo o por causas objetivas, las Autoridades Portuarias asumirán el coste de las indemnizaciones generadas desde la celebración de los contratos hasta su extinción o hasta el 14 de mayo de 2020, fin del periodo transitorio, si esta fecha es anterior.

Se exige para ello que el trabajador haya mantenido sin solución de continuidad su trabajo como estibador portuario y que no alcance la edad de jubilación en los tres años siguientes a la extinción contractual. 
La Autoridad Portuaria, previa verificación, deberá abonar el importe al empleador en el momento de la extinción contractual y distribuidos en un periodo de tres ańos a partir de la solicitud (se entiende del empleador).

La finalidad de la norma no plantea dudas. Ante un escenario nuevo, abierto, en el que las reglas de juego han cambiado, que puede facilitar la entrada de nueva competencia, la medida se plantea como una fórmula "para igualar la posición competitiva entre los actuales titulares de licencias [...] con aquellos nuevos que accedan a la prestación» y se activa en los supuestos de despido colectivo y despido por causas objetivas.

Es una medida que parece reunir los caracteres propios de las ayudas de Estado. De ahí la prudente cautela del apdo. 2 de la disposición final quinta del Real Decreto Ley 8/2017, que condiciona su efectividad hasta la expresa declaración por la Comisión de su compatibilidad con el régimen de ayudas de Estado.

Los requisitos que han de darse para que estemos ante una ayuda de Estado son conocidos (art. 107.1 TFUE): «Según reiterada jurisprudencia, la calificación de una medida de "ayuda de Estado", a efectos del artículo 107 TFUE, apartado 1, exige que concurran todos los requisitos siguientes. En primer lugar, debe tratarse de una intervención del Estado o mediante fondos estatales. En segundo lugar, tal intervención debe poder afectar a los intercambios comerciales entre los Estados miembros. En tercer lugar, debe conferir una ventaja selectiva a su beneficiario. En cuarto lugar, debe falsear o amenazar falsear la competencia (Sentencia de 6 de marzo de 2018, Comisión/FIH Holding y FIH Erhvervsbank, C-579/16 P, EU:C:2018:159 apartado 43 y jurisprudencia citada ${ }^{23}$.

En el caso que nos ocupa, el hecho de que vayan a ser los organismos públicos gestores de los puertos de interés general quienes se hagan cargo del abono de la medida no sería un obstáculo para entender cumplido el primero de los requisitos citados, el origen estatal de la ayuda.

En ese sentido, la jurisprudencia comunitaria ${ }^{24}$ ha señalado que «con objeto de determinar si la ventaja ha sido concedida directa o indirectamente mediante fondos estatales, debe recordarse que, de acuerdo con reiterada jurisprudencia del Tribunal de Justicia, la prohibición expresada en el artículo 107 TFUE, apdo. 1, incluye tanto las ayudas otorgadas directamente por el Estado o mediante fondos estatales como las otorgadas por organismos públicos o privados creados o designados por él para gestionar la ayuda, ya que el Derecho de la Unión no puede admitir que el mero hecho de crear instituciones autónomas encargadas de la distribución de ayudas permita eludir las normas relativas a las ayudas de Estado».

23 Sentencia del Tribunal de Justicia de la Unión Europea (Sala Segunda) de 29 de julio de 2019, C-659(17, ECLI:EU:C:2019:633, apdo. 20.

24 Por todas, Sentencia del Tribunal de Justicia de la Unión Europea (Sala Cuarta) de 15 de mayo de 2019, C-706/17, apdos. 50 y 51 y jurisprudencia allí citada. 
Aunque pueda afirmarse el carácter empresarial de las Autoridades Portuarias $^{25}$ y cuestionarse por lo tanto que su actividad pueda considerarse íntegramente como la de una autoridad pública, sin duda al compensar por mandato legal a las empresas estibadoras por el despido de trabajadores portuarios por las causas de los arts. 51 y 52 ET, no estarán tomando decisiones empresariales en condiciones de mercado, sino cumpliendo un mandato de aprobado por el Estado a través de un Real Decreto Ley ${ }^{26}$. Por ello, de acuerdo con la jurisprudencia comunitaria, tales medidas "deben considerarse imputables al Estado»"

Por esta razón, la medida que comentamos cumpliría el requisito de ser de origen estatal, imputable al Estado.

En cuanto a la afectación a intercambios comunitarios, cabe recordar que la jurisprudencia comunitaria no exige su acreditación efectiva, pero sí que sea razonable concluir que esa afectación puede producirse. Así, dice el tribunal que «a efectos de calificar una medida nacional como "ayuda de Estado", no es necesario acreditar la incidencia real de la ayuda de que se trate en los intercambios comerciales entre Estados miembros y la distorsión efectiva de la competencia, sino únicamente examinar si tal ayuda puede afectar a dichos intercambios y falsear la competencia» ${ }^{28}$, si bien "debe determinarse el motivo por el que la medida considerada puede afectar, por sus efectos previsibles, los intercambios entre los Estados miembros» ${ }^{29} \mathrm{Al}$ respecto, el hecho de tratarse de empresas que operan en puertos de interés general, puertos que forman parte en su mayoría de la RTE-T, apunta a la relevancia que la medida que comentamos puede tener para los intercambios comunitarios.

No parece discutible que la medida contemplada en la disposición transitoria primera, 4, del Real Decreto Ley 8/2017 constituye una ventaja para las

25 Sobre la consideración de las Autoridades Portuarias como empresas puede verse R. Eguinoa de San Román (2017), Derecho comunitario y puertos de interés general, Barcelona: Atelier, págs. 164-180 y 197-200.

26 Como indica la Comisión en su Comunicación 2016/C 262/01 relativa al concepto de ayuda estatal conforme a lo dispuesto en el art. 107.1 TFUE, cuando la ventaja se concede a través de una empresa pública, la imputabilidad al Estado no es automática, pero puede deducirse de un conjunto de indicios derivados de las circunstancias del asunto y del contexto en el que se adoptó la medida. Entre ellas el hecho de que la empresa a través de la que se concedió la ayuda estuviera obligada a tener en cuenta directrices de organismos gubernamentales (letra c) del apdo. 43, epígrafe 3.1.1. Indicios de imputabilidad).

27 En ese sentido, Sentencia del Tribunal de Justicia de la Unión Europea (Sala Cuarta) de 15 de mayo de 2019, C-706/17, apdo. 49.

28 Sentencia del Tribunal de Justicia de la Unión Europea (Sala Segunda) de 29 de julio de 2019, C-659/17 (apdo. 29) y jurisprudencia allí citada.

29 Sentencia del Tribunal de Justicia de la Unión Europea (Sala Cuarta) de 15 de mayo de 2019, C-706/17 (apdo. 90) y jurisprudencia allí citada. 
empresas $^{30}$ beneficiarias (SAGEP y empresas estibadoras que tengan contratado personal portuario a fecha 11 de diciembre de 2014), puesto que las favorece de forma directa.

La selectividad de la medida tampoco parece plantear dudas, puesto que solo se refiere a las SAGEP y a las empresas que tengan trabajadores portuarios con contrato antes del 11 de diciembre de 2014. El TJCE tiene una consolidada doctrina sobre el criterio de la especificidad de las medidas, en el sentido de defender que una medida es selectiva cuando no es aplicable a todas las empresas de un Estado, de manera que favorece exclusivamente a determinadas empresas o producciones $^{31}$.

En cuanto al último de los requisitos caracterizadores de las ayudas de Estado, a saber, el falseamiento de la competencia o la amenaza de que la medida falsee la competencia, cabe recordar que la jurisprudencia ha señalado que no es necesario acreditar el falseamiento, sino solo que la medida pueda producirlo, determinando las razones que llevan a esa consideración, indicando que "debe recordarse que las ayudas cuyo objetivo es liberar a una empresa de los costes propios de su gestión corriente o de sus actividades normales con los que normalmente debería haber cargado, falsean en principio las condiciones de competencia ${ }^{32}$. La medida que estamos examinando pretende dejar indemnes de los costes de despido (total o parcialmente) a las empresas beneficiarias.

Por todo lo expuesto, entendemos que la medida prevista en el apdo. cuatro de la disposición transitoria primera del Real Decreto Ley 8/2017 reviste los caracteres propios de las ayudas de Estado ${ }^{33}$. Hasta la fecha no se ha recibido ningún pronunciamiento de la Comisión sobre esta cuestión, por lo que un elemento clave de la reforma de la estiba está aún pendiente de confirmación.

3. El aval legal a la subrogación convencional (art. 4 del Real Decreto Ley 9/2019).

30 Sobre el concepto de empresa en derecho comunitario, puede verse, por todas, la Sentencia del Tribunal de Justicia de la Unión Europea de 1 de julio de 2008, TJCE 2008/148. Caso Motosykletistiki Omospondia Ellados NPID (MOTOE) contra Elliniko Dimosio.

31 En ese sentido, puede verse B. Pérez Bernabéu (2008), Ayudas de Estado en la jurisprudencia comunitaria. Concepto y tratamiento, Valencia: Tirant lo Blanch, págs. 42-52.

32 Sentencia del Tribunal de Justicia de la Unión Europea (Sala Cuarta) de 15 de mayo de 2019, C-706/17, apdo. 126 y jurisprudencia allí citada.

33 Aunque así fuera, cabe recordar que ello no obstaría a que la medida que comentamos pudiera llegar a ser declarada compatible con el mercado común por entenderse como una de las denominadas ayudas automáticas o incondicionadas o compatibles con el mercado común del art. 107.2 TFUE (aunque no acabamos de ver que se trate de un supuesto que encaje en ninguno de los contemplados en ese apartado), o bien que pudiera ser declarada compatible por perseguir alguno de los objetivos previstos en el art. 107.3 (cosa que nos parece igualmente dudosa) o incluso que se llegase a declarar su compatibilidad por la vía excepcional del art. 108.2 TFUE. 
La necesidad de reformar la regulación del régimen de gestión de los trabajadores de la estiba planteaba muchos interrogantes y muchos puntos conflictivos en el sector. Sin duda, uno de los más relevantes fue el relativo a la subrogación de las empresas estibadoras como empleadores de los trabajadores de las SAGEP ${ }^{34}$.

La subrogación se recomendaba en la Propuesta de Mediación incorporada como anexo al Real Decreto Ley 8/2017, aunque aparentemente referida a la "actividad empresarial de puesta a disposición de trabajadores portuarios»" ${ }^{35}, \mathrm{y}$, según su disposición final segunda, el Gobierno debía dictar un Real Decreto que aprobase dicha propuesta.

El Real Decreto no llegó a dictarse, pero, una vez convalidado el Real Decreto Ley, los agentes sociales acordaron con celeridad una modificación del IV Acuerdo del sector de la estiba portuaria, modificación que incorporaba al mismo la subrogación voluntaria del personal de las SAGEP a las empresas titulares de licencias ${ }^{36}$. Tal subrogación procedería en dos supuestos:

1) en caso de separación de alguna(s) empresa(s) de la SAGEP, la empresa o empresa que abandonara la SAGEP debería subrogarse en la posición de esta respecto de su plantilla en proporción a su participación accionarial $y$

2) en caso de liquidación de la SAGEP por separación de todas las empresas, igualmente los trabajadores tendrían derecho a la subrogación en las empresas estibadoras en proporción a su participación accionarial.

Esta modificación del IV Acuerdo ha sido cuestionada por la CNMC, con un expediente sancionador que ponía en tela de juicio los acuerdos alcanzados ${ }^{37}$.

34 Puede verse https//elpais.com>2017/03/21/actualidad/1490102612_166367. El Gobierno ve inviable la contrapropuesta de los estibadores... «El principal escollo para conseguir un acuerdo sigue siendo la petición de los trabajadores de incluir la subrogación en el decreto ley, algo a lo que el Ejecutivo no está dispuesto».

35 Punto 2 del epígrafe A, "Continuidad en el empleo», de la propuesta de Mediación.

36 Disposición adicional 7a del IV Acuerdo del sector de la estiba portuaria, introducida por Acta firmada el 6 de julio de 2017 ( $B O E$ de 18 de julio de 2017) y modificada para incluir una regulación mucho más detallada del proceso de subrogación por Acta firmada el 30 de enero de 2018 (BOE de 13 de marzo de 2018).

37 El 2 de noviembre de 2017 la Comisión Nacional de Mercados y Competencia incoó expediente (S/DC7 619/17) en relación con el acuerdo marco de la estiba, expediente dirigido — según la nota publicada por la CNMC el 6 de noviembre siguiente- contra patronal y sindicatos por posibles prácticas anticompetitivas, que consistirían en la restricción de la libertad de contratación de trabajadores para la prestación del servicio portuario de manipulación de mercancías y en la limitación de la libertad de las empresas prestadoras de dicho servicio de participar o no en sociedades cuyo objeto social sea la puesta a disposición de los citados trabajadores. 
Es en este contexto en el que se aprobó el Real Decreto Ley 9/2019 que, en su art. 4.1., da expresa cobertura legal a la posibilidad de subrogación convencional, ya incluida en el IV Acuerdo marco del sector: «las organizaciones sindicales y las asociaciones empresariales podrán establecer, mediante un acuerdo o un convenio colectivo, las medidas de subrogación necesarias para el mantenimiento del empleo de los trabajadores que» a la entrada en vigor del Real Decreto Ley 8/2017, «estuvieran prestando servicios portuarios de manipulación de mercancías y sigan prestándolo a la entrada en vigor del presente, en los supuestos previstos en los siguientes apartados».

A la vista de esta nueva regulación, la CNMC ha planteado una cuestión prejudicial a la Comisión Europea, dejando en suspenso el expediente sancionador relativo a la modificación del IV Acuerdo del sector antes citado ${ }^{38}$.

Cabe recordar que no es la primera vez que la autoridad nacional de la Competencia ejerce sus potestades sancionadoras en relación con este IV Acuerdo Marco: así por Resolución de 24 de septiembre de 2009 (expediente sancionador 2805/07) sancionó a los firmantes del Acuerdo por infracción del art. 1 de la Ley 16/1989 y del art. 81 del Tratado de la Comunidad Europea, por contener el mismo disposiciones por las cuales extendía su aplicación a empresas terceras, impidiéndoles o dificultándoles el acceso al mercado de los servicios complementarios en los puertos. La decisión de Competencia fue confirmada (aunque con reducción de la multa) por la Sentencia de la Audiencia Nacional de 5 de julio de 2013 y la Sentencia del Tribunal Supremo de 8 de marzo de 2016 (ECLI:ES:TS:2016:1069).

38 La CNMC formula las siguientes cuestiones atendido que el Real Decreto Ley puede tener cierto efecto retroactivo: «1 - ¿Debe el artículo 101 del TFUE interpretarse de forma que se consideren prohibidos los acuerdos entre operadores y representantes de los trabajadores, incluso bajo la denominación de convenios colectivos, cuando determinan la subrogación de los trabajadores vinculados con la SAGEP por parte de las empresas que se separan de ella y el modo en que la citada subrogación se realiza? 2 - En caso de que la respuesta a la anterior pregunta sea positiva, ¿¿debe interpretarse el artículo 101 del TFUE en el sentido de que se opone a disposiciones del Derecho interno como las contenidas en el Real Decreto Ley 9/2019 en la medida en que ampara los convenios colectivos que imponen una determinada forma de subrogación de trabajadores que desborda las cuestiones laborales y genera una armonización de condiciones comerciales? 3 - En caso de considerar que las citadas disposiciones legales resultan contrarias al Derecho de la Unión, ¿debe interpretarse la jurisprudencia de ese Tribunal sobre la primacía del Derecho de la UE y sus consecuencias, contenidas entre otras en las sentencias Simmenthal y Fratelli Costanzo, en el sentido de obligar a un organismo de Derecho Público como la Comisión Nacional de los Mercados y de la Competencia a dejar inaplicadas las disposiciones del derecho interno contrarias al artículo 101 del TFUE? 4 - En el caso de que la respuesta a la primera pregunta sea afirmativa, ¿deben interpretarse el art. 101 TFUE y el Reglamento (CE) no 1/2003 del Consejo de 16 de diciembre de 2002 relativo a la aplicación de las normas sobre competencia previstas en los artículos 81 y 82 del Tratado, y la obligación de asegurar la efectividad de las normas de la UE, en el sentido de requerir de una autoridad administrativa como la Comisión Nacional de los Mercados y de la Competencia la 
Al margen de la cuestión formulada por la CNMC, así como de las que pueda suscitar la propia formulación de una cuestión prejudicial por dicho organismo, expondremos a continuación nuestras consideraciones sobre el art. 4 del Real Decreto Ley 9/2019.

Como vimos, el precepto en cuestión se refiere al establecimiento de subrogación por acuerdo o convenio colectivo en el supuesto de que las empresas titulares de licencia para la prestación del servicio portuario opten por dejar la SAGEP con decrecimiento de la actividad o acuerden la disolución de la SAGEP (art. 4.2) y al supuesto de subrogación por transformación de la SAGEP en un CPE (art. 4.3). En el primer caso, las empresas estibadoras se subrogan en la posición de la SAGEP que dejan o que se disuelve, estableciéndose un sistema para distribuir los trabajadores y, en el segundo caso, el CPE pasa a ocupar la posición de la SAGEP.

Con esta regulación se ha pretendido proteger la posición de los trabajadores anteriores a la Sentencia del Tribunal de Justicia de la Unión Europea y poner fin al riesgo de quiebra de paz social en los puertos y la consiguiente perturbación de su explotación, preocupación que sin duda ha pesado también en las empresas del sector partidarias del acuerdo.

Ahora bien, la subrogación convencional en el supuesto contemplado en el art. 4.2 del Real Decreto Ley 9/2019 puede tener, sobre el papel, importantes consecuencias en el mercado de trabajo de la estiba de los puertos de interés general y en la cobertura de sus necesidades.

Sin perjuicio de que haga falta un estudio riguroso sobre el mercado, no parece temerario afirmar que el grueso de las necesidades de trabajo en el sector de la estiba se cubre actualmente con trabajadores portuarios que tenían contrato al entrar en vigor el Real Decreto Ley 8/2017.

De alguna forma, la medida que comentamos está facilitando que dichos trabajadores sigan cubriendo esas necesidades, con independencia de la desaparición de las obligaciones de que la contratación de estibadores se haga vía SAGEP y de participar en las SAGEP.

Ciertamente, siempre cabe que los trabajadores sigan como personal de un CPE — participado por empresas estibadoras — o una ETT, si las SAGEP se transforman o que los trabajadores opten por la rescisión voluntaria de sus contratos y soliciten las ayudas previstas en el Real Decreto 257/2019 ${ }^{39}$. Pero la posibilidad de que se den los supuestos de subrogación convencional existe. Llevada

imposición de multas sancionadoras y multas coercitivas a las entidades que llevan a cabo comportamientos como los descritos?».

39 Se estimaba en 542 el número máximo de potenciales beneficiarios de las ayudas para la adaptación del sector de la estiba portuaria por rescisión voluntaria del contrato de trabajo, de un total de 6156 trabajadores, según la Memoria de Análisis de Impacto Normativo del Proyecto de Real Decreto por el que se establecen las normas para la concesión de ayudas especiales para la adaptación del sector de la estiba portuaria, de 1 de abril de 2019, Ministerio de Trabajo, Migraciones y Seguridad Social, Secretaría General Técnica. 
al extremo podría suceder que todas las SAGEP desapareciesen y sus accionistas absorbieran a todos sus trabajadores portuarios.

En tal supuesto, salvo que en los próximos años se produjera un incremento relevante de tráfico portuario y una entrada masiva de nuevos operadores, se habría establecido una medida que posibilitaría que la cobertura del grueso de las necesidades de mano de obra de estiba se llevara a cabo por unos trabajadores portuarios determinados, los que tuvieran contrato en el momento de entrada en vigor del Real Decreto Ley 8/2017. Cabría entender que esta medida podría estar dificultando la llegada de nuevos trabajadores al mercado de la estiba.

Este tema se complica si se advierte que, con la subrogación convencional de empresas estibadoras en la posición de las SAGEP, puede estar forzándose la figura del traspaso empresarial. Decimos esto porque, así como en la subrogación de los CPE en la posición de las SAGEP pueden concurrir los requisitos que exige la jurisprudencia para entender que se produce un traspaso de empresa ${ }^{40}$, no sucede tan claramente en el caso de las empresas estibadoras, en la medida en que puede cuestionarse que aquellas continúan explotando la misma actividad que estas últimas.

Como es sabido, el Real Decreto Legislativo 2/2015, de 23 de octubre, por el que se aprueba el texto refundido del Estatuto de los Trabajadores regula la subrogación empresarial en el art. 44. Dicho artículo establece en su apdo. 2 que «se considerará que existe sucesión de empresa cuando la transmisión afecte a una entidad económica que mantenga su identidad, entendida como un conjunto de medios organizados a fin de llevar a cabo una actividad económica, esencial o accesoria».

En tales supuestos, señala el art. 44.1, quedará «el nuevo empresario subrogado en los derechos y obligaciones laborales y de Seguridad Social del anterior, incluyendo los compromisos de pensiones, en los términos previstos en su normativa específica, y, en general, cuantas obligaciones en materia de protección social complementaria hubiere adquirido el cedente».

Por su parte, el art. 1.1 de la Directiva 2001/23/CE relativa al mantenimiento de los derechos de los trabajadores en caso de traspasos de empresas o centros de actividad, establece en sus dos primeras letras: «a) La presente Directiva se aplicará a los traspasos de empresas, de centros de actividad o de partes de empresas o centros de actividad a otro empresario como resultado de una cesión contractual o de una fusión. b) Sin perjuicio de lo dispuesto en la letra a) y de las siguientes disposiciones del presente artículo, se considerará traspaso a los efectos de la presente Directiva el de una entidad económica que mantenga su identidad, entendida como un conjunto de medios organizados, a fin de llevar a cabo una actividad económica, ya fuere esencial o accesoria».

40 Sentencia del Tribunal de Justicia de la Unión Europea (Sala 4a) de 13 de septiembre de 2007, C-458/05, Jouini. 
Como ha señalado la doctrina, la parquedad de las definiciones legales convierte esta materia en campo abonado para que en la determinación de cuándo estamos ante un supuesto de sucesión empresarial tenga un papel estelar la jurisprudencia. Aunque no es objeto de este trabajo llevar a cabo un estudio de la sucesión de empresas, ni de los presupuestos que deben darse para interpretar que esta se produce y procede, por tanto, la subrogación ${ }^{41}$, sí recordaremos que, entre los presupuestos exigidos por la jurisprudencia tanto comunitaria como nacional para la existencia de traspaso de empresas, determinante de la obligación de subrogación empresarial, está el de la continuidad de la actividad de la empresa cesionaria.

En ese sentido, dice el tribunal: «Según la jurisprudencia del Tribunal de Justicia [...] el criterio decisivo para determinar la existencia de una transmisión de una empresa o de una parte de una empresa en el sentido de la Directiva es el del mantenimiento de la identidad de la entidad económica. Según esta misma jurisprudencia, el mantenimiento de esta identidad es consecuencia en particular de que el nuevo empresario continúe efectivamente o retome las mismas actividades económicas o actividades análogas» ${ }^{42}$.

Sin perjuicio de que no sea este el único elemento que debe darse para que haya traspaso empresarial, su presencia es necesaria para ello ${ }^{43}$.

Pues bien, en el supuesto del art. 4.2 del Real Decreto Ley 9/2019 sin duda se produce una transferencia de trabajadores de las SAGEP a las empresas estibadoras, pero los negocios de estas empresas son diferentes, no coinciden. No hay una identidad entre la actividad de las empresas estibadoras y las SAGEP, aquellas no continúan la explotación de estas.

41 Entre otros muchos pueden verse O. Fernández Márquez (2019) «El objeto de la transmisión: el concepto de unidad económica productiva autónoma», M. ${ }^{a}$ Y Sánchez-Urán Azaña (2019), «La sucesión de plantillas como factor determinante de la transmisión de empresas» y J. Gil Plana, (2019), «La subrogación empresarial impuesta por convenio colectivo: condiciones y efectos», todos ellos en Joaquín García Murcia (dir.), Transmisión de Empresa y Sucesión en el desarrollo de Actividades Empresariales. Un estudio a partir de la jurisprudencia del Tribunal Supremo, Pamplona: Editorial Aranzadi SAU, págs. 39 y ss, 137 y ss y 201 y ss respectivamente.

Sentencia del Tribunal de Justicia (Sala 5a) de 14 de abril de 1994, C-392/92, apdo. 17.

43

«Partiendo del art. 1.1 de la Directiva 2001/23, el mantenimiento de la identidad es el elemento decisivo para determinar si estamos ante una transmisión (TJUE 18-3-86, Spikers C-24/85); pero se refiere a la identidad de la actividad que vaya acompañada de la cesión de elementos significativos del activo material o inmaterial (TJUE 14-4-94, Schmidt C-392/92; 11-3-97, Süzen C-13/95)». I. Arastey Sahún (2019), «Aspectos laborales del traspaso de empresas (Directiva 2001/23/CE del Consejo, de 12 de marzo de 2001)", en M. a Emilia Casas Baamonde y Román Gil Alburquerque (dirs.), Derecho Social de la Unión Europea Aplicación por el Tribunal de Justicia, Madrid: Lefevre-El Derecho, pág. 1017. 
La actividad de la SAGEP es la puesta de trabajadores portuarios a disposición de las empresas estibadoras, así como la formación de dichos trabajadores ${ }^{44}$. La actividad de las empresas estibadoras, en cambio, es la prestación del servicio portuario de manipulación de mercancías.

Visto lo anterior, estaríamos ante una normativa que, por la fórmula de forzar la figura del traspaso empresarial, estaría provocando el efecto de hacer menos atractivo el mercado laboral de la estiba español para los trabajadores de los otros Estados miembros, convirtiéndolo en un mercado con menos oportunidades de trabajo de las que habría tenido sin esa regulación ${ }^{45}$.

Como se recordará, el art. 45 del TFUE proclama la libre circulación de trabajadores dentro de la Unión y establece, en su apdo. 2, que: «La libre circulación supondrá la abolición de toda discriminación por razón de la nacionalidad entre los trabajadores de los Estados miembros, con respecto al empleo, la retribución y las demás condiciones de trabajo».

Según la jurisprudencia comunitaria, el precepto transcrito prohíbe no solo discriminaciones manifiestas, basadas en la nacionalidad, sino también «cualquier forma de discriminación encubierta que, aplicando otros criterios, conduzca de hecho al mismo resultado", debiendo considerarse indirectamente discriminatoria aquella medida que, «por su propia naturaleza, pueda afectar más a los trabajadores migrantes que a los trabajadores nacionales e implique por consiguiente el riesgo de perjudicar, en particular, a los primeros» y debiéndose tener en cuenta que «para que pueda calificarse una medida como indirectamente discriminatoria no es necesario que tenga como efecto favorecer a todos los nacionales del Estado miembro interesado, o desfavorecer solo a los nacionales de otros Estados miembros, con exclusión de los primeros» ${ }^{46}$.

Por ello, el TJUE ha establecido que las normas de Derecho comunitario "prohíben las medidas nacionales que impiden o disuaden a los nacionales de un Estado miembro de abandonar su Estado de origen para ejercer su derecho a la libre circulación en territorio de la Unión», puesto que esas medidas, «aunque se apliquen con independencia de la nacionalidad de las personas afectadas, constituyen obstáculos a las libertades fundamentales garantizadas por dichos artículos» ${ }^{47}$.

44 I. Ballester Pastor (2014: 23): «A día de hoy la SAGEP no usa a los estibadores para llevar a cabo las tareas propias o características de esta actividad profesional, sino que únicamente reserva, forma y presta a estos trabajadores cuando las empresas estibadoras los necesiten de forma temporal o bien de forma indefinida o con mayor vinculación temporal. [...] Por tanto, la SAGEP, cuando actúa como empleador de los estibadores en relación laboral especial, lo hace de forma semejante a como lo hace hoy en día una ETT [...]».

45 Aparte de que con esta regulación se refuerza el eventual impacto de la medida del apdo. 4 de la disposición transitoria primera del Real Decreto Ley 8/2017.

46 Sentencia del Tribunal de Justicia de la Unión Europea de 5 de diciembre de 2013, C-514/12.

47 Por todas, Sentencia del Tribunal de Justicia de la Unión Europea de 8 de mayo de 2013 acumulados C-197/11 y C-203/11, apdo. 38 y jurisprudencia allí citada. 
Por otra parte, cabe recordar que la jurisprudencia comunitaria ha declarado reiteradamente que el derecho de los trabajadores a ser contratados y empleados sin sufrir discriminación, para ser eficaz y útil, debe tener necesariamente como complemento el derecho de los empresarios a contratarlos con arreglo a las normas que rigen en materia de libre circulación de trabajadores ${ }^{48}$. Este derecho de los empresarios también se vería afectado por la regulación de la subrogación que estamos comentando, que, además, podría desincentivarles para separarse de las SAGEP.

Ciertamente, todo ello podría ser admisible desde el punto de vista del derecho comunitario, pero sería preciso que el Estado lo justificara adecuadamente.

En ese sentido, la jurisprudencia comunitaria ha señalado que «una medida que restringe la libre circulación de los trabajadores sólo puede justificarse si persigue un objetivo legítimo compatible con el Tratado y se justifica por razones imperiosas de interés general. En tal caso, también es necesario que la aplicación de la medida de que se trata sea adecuada para garantizar la realización del objetivo que persigue y no vaya más allá de lo que es necesario para alcanzar dicho objetivo».

Es responsabilidad de «los Estados miembros, al adoptar una medida que supone una excepción a un principio reconocido por el derecho de la Unión, probar, en cada caso, que dicha medida para garantizar la consecución del objetivo invocado y que no excede de lo necesario para alcanzarlo. Por tanto, las razones justificativas que puede invocar un Estado miembro deben ir acompańadas de un examen de la idoneidad y de la proporcionalidad de la medida adoptada por dicho Estado y de datos precisos en los que pueda sustentarse su alegación» ${ }^{49}$.

Por lo expuesto, se plantean dudas sobre la plena adecuación al derecho comunitario de la regulación de la subrogación convencional en el art. 4 del Real Decreto Ley 9/2019. Por otra parte, esta posibilidad de subrogación de las empresas estibadoras como empleadoras de trabajadores portuarios de las SAGEP da mayor relevancia al posible impacto de la medida prevista en la disposición transitoria primera, 4, del Real Decreto Ley 8/2017 y, precisamente por ello, refuerza la importancia de dicha medida en la transición al nuevo régimen de la estiba.

\section{RECAPITULACIÓN}

La Sentencia del TJUE de 11 de diciembre de 2014 ha obligado a revisar el modelo laboral del servicio portuario de manipulación de mercancías en los puertos de interés general que estaba vigente desde mediados de los años ochenta

48 Por todas, Sentencia del Tribunal de Justicia de la Unión Europea (Sala Tercera) de 11 de enero de 2007, asunto C-208/05, apado. 23 y jurisprudencia allí citada.

49 Por todas, Sentencia del Tribunal de Justicia de la Unión Europea de diciembre de 2012, C-379/11, apdos. 48 y 49 y jurisprudencia allí citada. 
por estimar que, en definitiva, establecía restricciones no justificadas a la libertad de establecimiento.

La reforma realizada por los Reales Decretos Leyes 8/2017 y 9/2019, así como el Real Decreto 257/2019, configura un nuevo modelo y unas condiciones de transición al mismo. Así como el nuevo modelo cumple, a nuestro juicio, las exigencias de la Sentencia del TJUE, la compatibilidad con el derecho comunitario de algunas de las condiciones establecidas para posibilitar la transición puede cuestionarse.

La asunción por parte del Estado, vía Autoridades Portuarias, del coste de las indemnizaciones en caso de despido colectivo o de despido por causas objetivas (apdo. 4, disposición transitoria primera Real Decreto Ley 8/2017) presenta caracteres propios de las ayudas de Estado y por eso su entrada en vigor está condicionada a una declaración de la Comisión europea sobre su compatibilidad con el régimen de ayudas de Estado, compatibilidad que, desde nuestro de vista, es complicada.

La admisión de que pueda acordarse por convenio la subrogación de las empresas estibadoras accionistas de las SAGEP en la posición de estas como empleadoras de los trabajadores del servicio portuario de manipulación de mercancías (art. 4 Real Decreto Ley 9/2019), puede constituir, según hemos expuesto, una restricción a la libre circulación de trabajadores contraria al Tratado. Por otra parte, la CNMC ha formulado cuestión prejudicial ante la Comisión Europea.

Habida cuenta de la importancia que estas condiciones han tenido en el proceso de reforma de la estiba habrá que esperar con atención los próximos pronunciamientos de la Comisión Europea. En estas circunstancias, puede decirse que, de alguna manera, la reforma del servicio portuario de manipulación de mercancías está pendiente de confirmación. 
